\title{
Metodologia do ensino superior na pandemia da COVID-19: Experiência no desenvolvimento de curso sobre Scoping Review em plataformas digitais
}

Higher education methodology in the COVID-19 pandemic: Experience in the development of a course on Scoping Review on digital platforms

Metodología de la educación superior en la pandemia COVID-19: Experiencia en el desarrollo de un curso de Scoping Review en plataformas digitales Universidade Regional do Cariri, Brasil

E-mail: liviamr.ce@ hotmail.com

Luanna Gomes da Silva

ORDID: https://orcid.org./0000-0001-8980-3405 Universidade Regional do Cariri, Brasil E-mail: luannagomes.s14@gmail.com

Grayce Alencar Albuquerque

ORDID: https://orcid.org/0000-0002-8726-0619 Universidade Regional do Cariri, Brasil

E-mail:grayce.alencar@urca.br

Maria do Socorro Vieira Lopes

ORDID: https://orcid.org/0000-0003-1335-5487 Universidade Regional do Cariri, Brasil E-mail:socorro.lopes@urca.br Álissan Karine Lima Martins

ORDID: https://orcid.org./0000-0002-9382-1144 Universidade Regional do Cariri, Brasil

E-mail: alissan.martins@urca.br

Edilma Gomes Rocha Cavalcante

ORCID: https://orcid.org/0000-0002-6861-2383 Universidade Regional do Cariri, Brasil E-mail: edilma.rocha@yahoo.com.br Maria Corina Amaral Viana

ORCID: https://orcid.org/0000-0002-6890-9400 Universidade Regional do Cariri, Brasil E-mail: corina.viana@urca.br

Glauberto da Silva Quirino

ORCID: https://orcid.org/0000-0001-5488-7071 Universidade Regional do Cariri, Brasil

E-mail: glauberto.quirino@urca.br

Evanira Rodrigues Maia

ORDID: https://orcid.org/0000-0001-9377-7430 Universidade Regional do Cariri, Brasil E-mail:evaniramaia@gmail.com 


\begin{abstract}
Resumo
O presente estudo teve como objetivo descrever o desenvolvimento e avaliação de curso à distância sobre Scoping Review e competências docentes de mestrandos de enfermagem. Trata-se de um relato de experiência sobre um curso desenvolvido entre maio e julho de 2020, em um mestrado acadêmico de enfermagem no Nordeste do Brasil, para capacitar mestrandos a elaborar formação por competências, aplicar instrumentos/métodos de avaliação e tutoria por meio de desenvolvimento de curso à distância. Dos 20 estudantes inscritos, concluíram 17. Curso desenvolvido em quatro módulos em atividades síncronas e assíncronas no Google Classroom e Google Meet, utilizando estratégias de ensino: leitura prévia, aula expositiva, tutoria, estudo dirigido e exercícios. Os métodos de avaliação foram pré-teste de múltipla escolha, assiduidade, tutoria, mapa conceitual, autoavaliação e pós-teste de múltipla escolha. A aplicação do curso em plataformas digitais mostrou ser uma estratégia eficaz e viável. As estratégias utilizadas favoreceram a aprendizagem sobre scoping review e o desenvolvimento de habilidades docentes e de tutoria nos mestrandos.
\end{abstract}

Palavras-chave: Educação à distância; Ensino; COVID-19.

\begin{abstract}
The present study aimed to describe the development and evaluation of distance learning courses on Scoping Review and teaching abilities of nursing master's students. This is an experience report about a course developed between May and July 2020, in an academic master's degree in nursing in the Northeast of Brazil, to capacitate master's students to develop competencies training, to apply instruments/methods of evaluation and tutoring. 20 students enrolled and 17 concluded. Course developed in four modules in synchronous and asynchronous activities in Google Classroom and Google Meet, using as teaching strategies: previous reading, exhibition class, tutoring, directed study and exercises. The evaluation methods were multiple choice pre-test, attendance, tutoring, conceptual map, selfassessment and multiple choice post-test. Course carried out on digital platforms proved to be an effective and viable strategy. The strategies used favored the learning about scoping review and the development of teaching skills and tutoring in master's students.
\end{abstract}

Keywords: Distance Education; Teaching; COVID-19.

\title{
Resumen
}

El presente estudio tuvo como objetivo describir el desarrollo y evaluación de curso la distancia sobre Scoping Review y competencias docentes de los estudiantes de maestría en enfermería. Este es un informe de experiencia sobre un curso desarrollado entre mayo y julio de 2020, en una maestría académica en enfermería en el noreste de Brasil, para formar a estudiantes de maestría para elaborar la formación en competencias, aplicar instrumentos/métodos de evaluación y tutoría através del desarrollo de curso la distancia. De los 20 estudiantes matriculados, 17 concluyeron. El curso se desarrolló en cuatro módulos en actividades sincrónicas y asincrónicas en Google Classroom y Google Meet, utilizando estrategias didácticas: lectura previa, clase de exposición, tutoría, estudio dirigido y ejercicios. Los métodos de evaluación fueron prueba previa de opción múltiple, presencia, tutoría, mapa conceptual, autoevaluación y prueba de opción múltiple. La aplicación del curso en plataformas digitales resultó ser una estrategia eficaz y viable. Las estrategias empleadas favorecieron el aprendizaje sobre la revisión del alcance y el desarrollo de habilidades docentes y tutoría en los estudiantes de maestría.

Palabras clave: Educación a distancia; Ensenãnza; COVID-19.

\section{Introdução}

O cenário mundial ocasionado pela pandemia do coronavírus (SARS-CoV-2), causador da COVID-19, resultou em mudanças para o setor da educação, na qual tecnologias e estratégias educacionais tiveram que ser implantadas para dar continuidade as atividades acadêmicas na graduação e pós-graduação. As plataformas e as mídias digitais, como o ambiente virtual de aprendizagem (AVA) se tornaram aliadas da educação mundial e brasileira favorecendo o desenvolvimento de um ensino criativo e inovador, com o desafio de atender às necessidades de ensino e aprendizagem dos estudantes (França et al., 2019).

Isto posto, os cursos à distância por meio de plataformas digitais são fundamentais para garantir o ensino, por ser um meio que possibilita a interação entre os sujeitos, fortalecendo a aprendizagem cooperativa e a autonomia educacional (Andrade \& Benati, 2019).

No Brasil, o Decreto no 2.494 da Presidência da República, que regulamenta o artigo 80 da Lei $N^{\circ}$ 9.394, de 20 de dezembro de 1996, de Diretrizes e Bases da Educação, destaca que a Educação a Distância (EaD) possibilita um processo de aprendizagem autônomo, no qual estudantes e professores utilizam recursos didáticos e meios tecnológicos que favorecem o desenvolvimento da argumentação e criticidade, sem excluir atividades presenciais (Brasil, 1996). 
Deste modo, em meio ao contexto atual de educação, manifestou-se a necessidade de continuidade do ensino na pósgraduação, ao nível de mestrado, por meio da adoção do ensino remoto. A elaboração de curso à distância a ser ministrado pelos estudantes mostrou-se como uma oportunidade de aprendizagem para promover o desenvolvimento de competências docentes dos futuros mestres em enfermagem.

Dentre as várias temáticas, destaca-se como relevante a inserção em cursos à distância a elaboração da Scoping Review, também conhecidas como "revisão de mapeamento" ou "estudos de escopo", um tipo de revisão da literatura inovadora que permite obter visão geral ou mapa das evidencias disponíveis sobre um tópico, identificação de lacunas existentes, proporcionando contribuições na elaboração de novas pesquisas na enfermagem (Peters et al., 2020).

Por se tratar de um tipo de revisão recente na produção científica, a Scoping Review é pouco conhecida no meio acadêmico e de enfermagem. Desse modo, capacitações voltadas para esta temática através da modalidade de ensino a distância é uma estratégia útil pois facilita o processo de adesão ao ensino no cenário atual de distanciamento social.

Este estudo objetiva descrever o desenvolvimento e avaliação de curso à distância sobre Scoping Review por meio de plataformas digitais e competências docentes de mestrandos de enfermagem.

\section{Metodologia}

Trata-se de um estudo qualitativo do tipo relato de experiência, de forma que carrega a interpretação e as opiniões do pesquisador sobre o fenômeno que está sendo estudado (Pereira et al., 2018). Foi realizado por estudantes do Curso de Mestrado acadêmico de uma Universidade Pública localizada na região Nordeste do Brasil, por meio de atividades síncronas e assíncronas na disciplina de Metodologia do Ensino Superior para desenvolvimento de curso à distância.

A construção do curso intitulado Revisão da Literatura Cientifica: Scoping Review ocorreu no período de maio a julho de 2020, mediante atividades síncronas na plataforma Google Meet para elaboração do plano de ensino contemplando: ementa, competências/objetivos específicos de aprendizagem, metodologias e estratégias de ensino, instrumentos de avaliação, recursos didáticos, conteúdo programático, carga horária e referências bibliográficas, sob supervisão das docentes da disciplina.

O curso foi ofertado na modalidade $\mathrm{EaD}$ por meio de atividades síncronas e assíncronas em quatro módulos, com carga horária de 20 horas, para estudantes de enfermagem. As plataformas digitais Google Classroom e Google Meet foram utilizadas para as atividades do curso. A estratégia de tutoria síncrona foi adotada para orientações e acompanhamento da realização das atividades.

\section{Resultados}

\subsection{Apresentação do curso}

A competência estabelecida para o curso foi capacidade de desenvolver as etapas de uma Scoping Review como preconizado pelo Joanna Briggs Institute - JBI. Na Figura 1, apresenta-se os quatro módulos do curso disponibilizados em períodos pré-estabelecidos, as competências/objetivos específicos, estratégias de ensino, métodos e instrumentos de avaliação utilizados, sendo cada módulo ministrado em dois dias, totalizando oito dias de atividades. As estratégias de ensino e avaliação contemplaram as dimensões cognitiva, procedimental/psicomotora e atitudinal, trabalhadas no cronograma do curso. 
Figura 1 - Fluxograma da organização do curso. Crato, Ceará, Brasil, 2020.

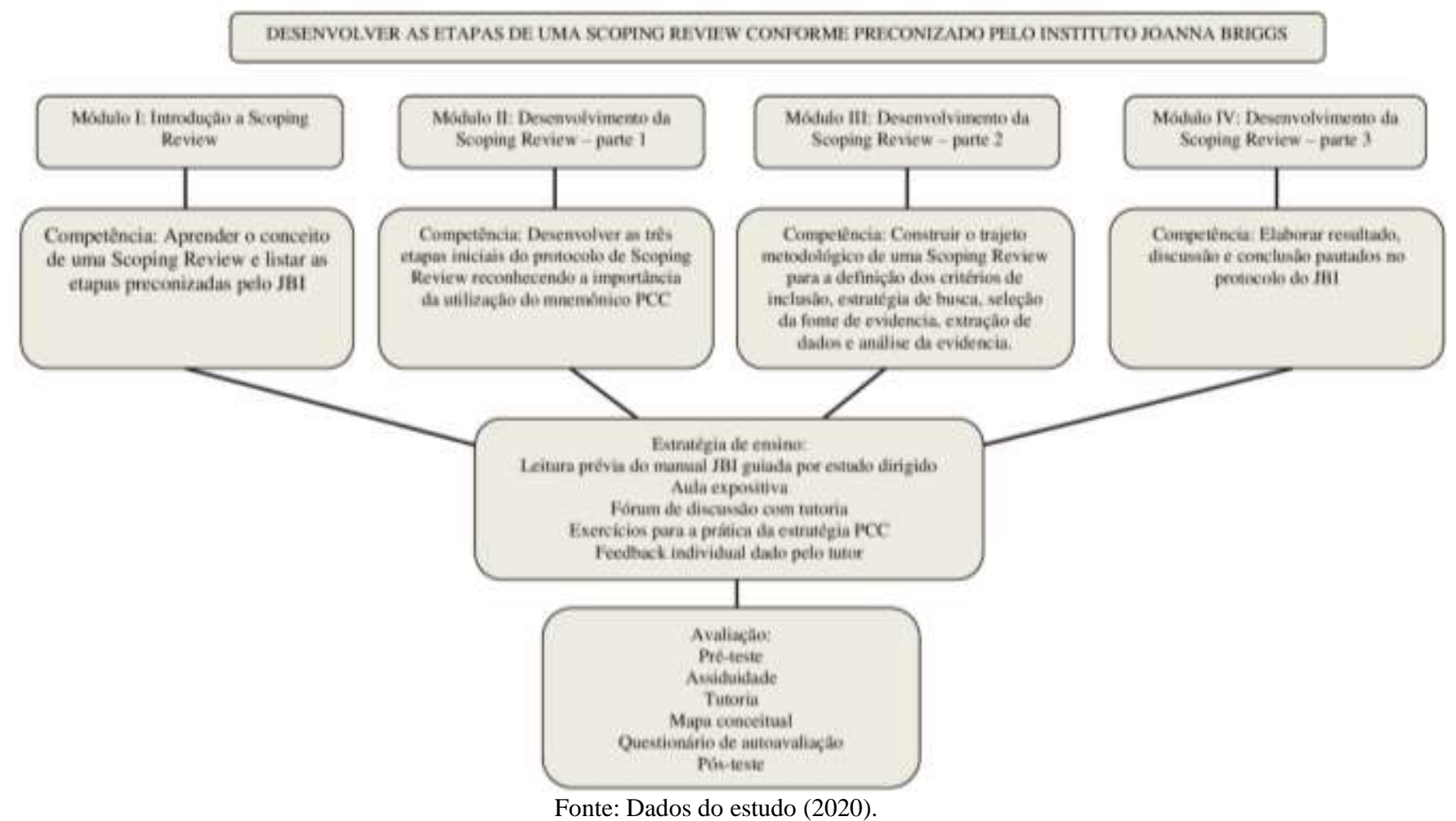

O primeiro contato das tutoras com a turma ocorreu por meio de atividade síncrona na plataforma Google Meet. O intuito do momento era desejar boas-vindas aos alunos e apresentar o curso, bem como, promover familiaridade dos estudantes com as plataformas utilizadas (Google Meete Google Classroom), além de sanar eventuais dúvidas dos cursistas.

Utilizou-se de linguagem simples, instrucional, buscando deixar os alunos à vontade para fazer perguntas por meio das ferramentas da plataforma (chat e/ou microfone), incentivando a interação com intenção de criar vínculo entre alunos e tutores. As dúvidas referentes ao uso das plataformas, programação do curso, reuniões online, frequência e assiduidade dos alunos foram sanadas no encontro.

Para o desenvolvimento da metodologia de ensino cognitiva foi realizado leitura prévia do manual JBI sobre elaboração de Scoping Review (Peters et al., 2020), aula expositiva elaborada pelas tutoras em formato $p d f$, estudo dirigido e exercícios sobre os conteúdos disponibilizados na plataforma Google Classroom.

A estratégia de estudo dirigido utilizada nos módulos I, III e IV foi composta por duas a quatro questões subjetivas, elaboradas com espelho resposta, sobre o conteúdo da leitura prévia disponibilizada na plataforma Google Classroom. Essas atividades proporcionaram as tutoras direcionamento do assunto abordado, apresentando exemplos e novas informações sobre o tema.

Os exercícios foram utilizados no módulo II e elaborados a partir de artigos atualizados publicados em periódicos nacionais para facilitar a compreensão e a prática do mnemônico PCC apresentado, como o exemplo a seguir (Quadro 1): 
Quadro 1 - Exemplo do exercício sobre Mnemônico PCC. Crato-CE, 2020.

\title{
Exercitando os conhecimentos sobre Mnemônico PCC
}

Questão 1. Para a construção de uma Scoping Review é recomendado o uso do mnemônico "PCC" como guia para título, objetivo e pergunta norteadora. O mnemônico PCC representa População, Conceito e Contexto. Nem sempre os três elementos do mnemônico estão explícitos, no entanto, elementos de cada um deles podem estar implícitos no conceito do estudo. Encontre o mnemônico PCC para o título a seguir:

A) TÍTULO "Intervenções comunitárias relacionadas à violência entre parceiros íntimos adolescentes: revisão de escopo".

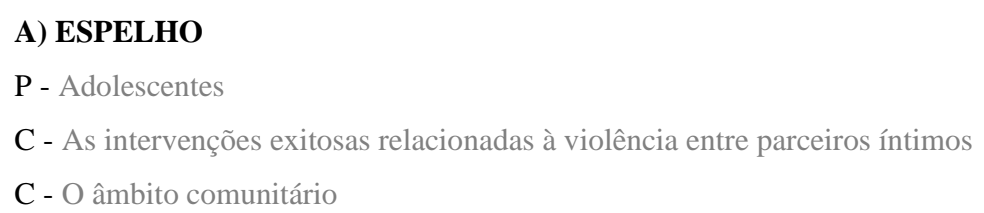

Questão 2. Reflita sobre os conhecimentos adquiridos no decorrer deste módulo e construa uma questão norteadora, objetivo de pesquisa e um possível título para artigo de Scoping Review a partir do mnêmônico "PCC".
A) MNEMÔNICO
P. Mulheres grávidas ou gestantes
C. A pandemia COVID-19 e o vírus SARS-CoV-2
C. Gravidez ou gestação

\begin{abstract}
A) ESPELHO
QUESTÃO NORTEADORA: Qual é a produção de conhecimento sobre as recomendações para a assistência à gestante no enfrentamento do novo Coronavírus?

OBJETIVO: Mapear a produção de conhecimento sobre as recomendações para a assistência à gestante no enfrentamento do novo Coronavírus.
\end{abstract}

TÍTULO: COVID-19 e a produção de conhecimento sobre as recomendações na gravidez: revisão de escopo.

Fonte: Dados dos estudos de Lourenço et al. (2019) e Mascarenhas et al. (2020).

A metodologia de ensino procedimental/psicomotora foi desenvolvida por meio de discussão e esclarecimento de dúvidas em atividade síncrona em cada módulo na plataforma Google Meet e nesse ambiente o tutor dialogava sobre o tema referente ao módulo, discutia as questões dos estudos dirigidos ou exercícios e os alunos participaram por meio do chat ou áudio/vídeo.

Como metodologia de ensino atitudinal, durante todo o curso os alunos foram acompanhados pelas tutoras, recebendo feedback imediato sobre a resolução das atividades propostas, participação e assiduidade durante o curso

\subsection{Caracterização dos participantes}

A turma foi composta por estudantes entre o primeiro e décimo semestre da graduação em enfermagem, totalizando 20 matriculados e 17 concludentes. Desses, 15 eram do sexo feminino e cinco eram do sexo masculino, com idade entre 19 a 36 anos, todos solteiros, procedentes de cidades localizadas nos estados de Pernambuco e Ceará.

Percebeu-se que grande parte da turma não estava familiarizada com as plataformas digitais e durante o curso solicitaram ajuda para o manuseio de ferramentas e softwares. No intuito de mitigar essas dificuldades, a tutoria criou um grupo no aplicativo WhatsApp com todas as tutoras e alunos para promover comunicação mais rápida e eficaz, prestar o acompanhamento individual para os alunos, como também, prazos e meios de construção das atividades foram flexibilizados. 


\subsection{Métodos de avaliação}

Durante o desenvolvimento do curso, a avaliação dos alunos se deu por meio de pré-teste de múltipla escolha, assiduidade (1,0 ponto), tutoria (3,0 pontos), mapa conceitual (3,0 pontos), questionário de autoavaliação (1,0 ponto) e pósteste de múltipla escolha (2,0 pontos). A nota final correspondeu ao somatório de todos esses critérios, sendo 7,0 pontos a nota mínima para aprovação. Dos 20 alunos matriculados no curso, dois desistiram durante o primeiro módulo e apenas um aluno atingiu pontuação inferior a 7,0 pontos, totalizando 17 concluintes. A média geral dos alunos correspondeu a 8,9.

Previamente foi aplicado teste de múltipla escolha de elaboração própria com sete questões, tipo pré-teste, para avaliar o conhecimento prévio dos alunos sobre a temática, sem pontuar na média final. Os resultados do pré e pós-teste foram utilizados para avaliar o desempenho dos 17 alunos que finalizaram o curso. A média no pré-teste foi de 0,77 pontos e no pósteste aumentou para 1,5 pontos ( $p<0,000002$, Teste t para grupos pareados).

$\mathrm{Na}$ Figura 2, observa-se que sete alunos obtiveram nota maior ou igual a 1,0 no pré-teste, enquanto 16 alunos obtiveram notas acima de 1,0 no pós-teste. Os resultados também mostram que 16 dos alunos obtiveram melhora na sua nota, em relação ao pré-teste.

Figura 2 - Distribuição da pontuação obtida pelos alunos no pré-teste e pós-teste. Crato, CE, Brasil, 2020.

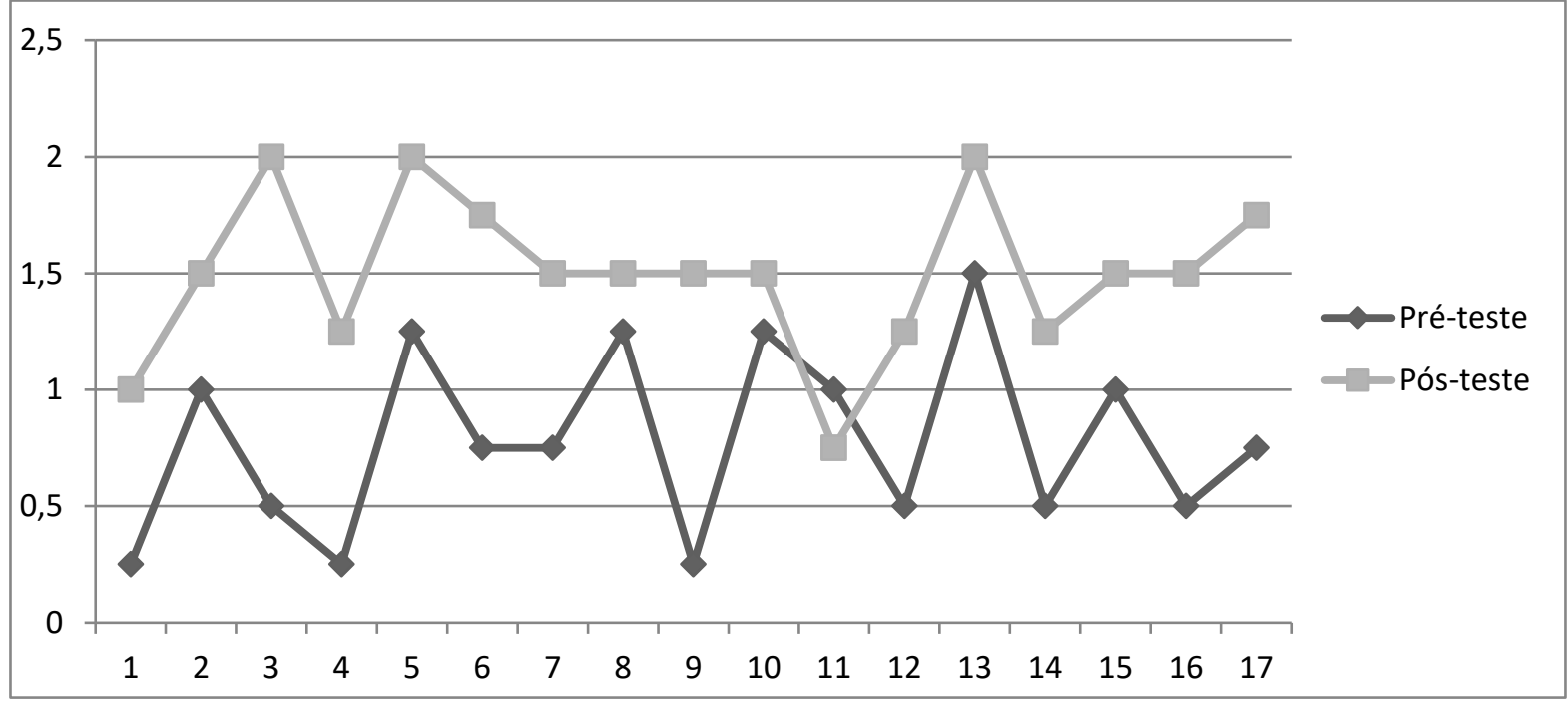

Fonte: Dados do estudo (2020).

A nota atribuída pela assiduidade correspondeu a $10 \%$ da nota geral do curso e considerou necessário o cumprimento mínimo de $75 \%$ da carga horária. A assiduidade variou de $87,5 \%$ a $97,5 \%$.

Para a construção do mapa conceitual orientou-se elaboração de modo contínuo utilizando o Software Cmap Tools disponível para download gratuito e tutorial no Youtube que orienta a utilização do software. Em cada módulo do curso, parte do mapa conceitual deveria ser elaborada contemplando os conteúdos apresentados, seguindo o modelo do tipo hierárquico. Considerou-se os critérios para avaliação propostos pela literatura: conceitos claros, relações coerentes, riqueza de ideias, criatividade na organização e representatividade do conteúdo trabalhado (Anastasiou \& Alves, 2009). Foram construídos 17 mapas, a nota variou de 2,0 a 3,0 pontos, com média final de 2,7.

Observou-se que a maioria dos cursistas elaboraram mapas conceituais demonstrando síntese clara, criativa e objetiva do conteúdo, detalhando as etapas do desenvolvimento de uma Scoping Review, dispuseram os conceitos de forma hierárquica com estética adequada na construção, destacaram os módulos por cores diferentes, atingindo de forma satisfatória os critérios 
de avaliação dos mapas conceituais. Ademais, alguns cursistas apresentaram dificuldade no download e utilização do Software Cmap Tools, optando por utilizar outras ferramentas para criar o mapa conceitual.

A autoavaliação foi estruturada com informações sobre sua aplicação, instruções para o preenchimento dos itens e questões objetivas e discursivas. As questões objetivas abordavam os seguintes aspectos: assiduidade, participação nos fóruns de discussão, relacionamento aluno/tutor avaliando o nível de confiança e de respeito desenvolvido, cumprimento de prazos e compreensão dos estudos individuais. Cada aspecto foi avaliado como ótimo (100\%), bom (75\%), regular (50\%) ou ruim (25\%). A maioria dos alunos avaliou o seu desempenho como ótimo e bom, considerando-se aptos para a aprovação no curso.

As questões discursivas abordaram a percepção dos alunos sobre o seu desempenho, avaliando se o objetivo de aprendizagem/competência pretendido foi alcançado, como também aspectos do desenvolvimento do curso que poderiam ser aprimorados. Todos avaliaram que o objetivo de aprendizagem proposto foi atingido e as respostas elucidaram pontos importantes para o aprimoramento das estratégias educacionais utilizadas, subsidiando a possibilidade de melhora para próximas edições do curso.

Os cursistas destacaram como pontos positivos a clareza e objetividade dos conteúdos, o material didático, a correção dos exercícios no grupo de discussão via Google meet, o material disponibilizado em português e vínculo das tutoras com a turma. Foi sugerida a gravação de aulas em vídeo ou realização de aulas remotas para substituir apenas leituras individuais de Power point, ampliar o tempo para a resolução das atividades, aumentar a quantidade de exercícios, desenvolver uma revisão durante o curso para praticar e avaliar o desenvolvimento das competências estabelecidas.

Quanto as vivências das tutoras, dentre muitos desafios, foram evidenciadas a falta de experiência em educação à distância, pouca habilidade com as plataformas digitais, barreiras relacionadas ao suporte limitado da tecnologia, maior familiaridade com o ensino presencial tanto para discentes como para docentes/mestrandos e baixa participação dos alunos nas aulas o que dificultou a comunicação tutor/aluno.

\section{Discussão}

No novo cenário mundial, em decorrência da pandemia gerada pela COVID-19, a educação tem passado por mudanças em relação ao formato das aulas, cursos e encontros presenciais. A metodologia à distância e o ensino remoto têm sido uma boa estratégia para o desenvolvimento de cursos e capacitações profissionais, objetivando manter o distanciamento, mas favorecendo a realização das atividades da educação básica, superior e pós-graduação, da educação permanente e continuada, apesar das desigualdades digitais.

As metodologias de ensino a distância objetivam minimizar os efeitos negativos da educação resultantes do distanciamento social, embora, alguns alunos ainda vivenciem limitações de acesso à tecnologia ou uso de internet (Brasil, 2020).

Os métodos de ensino elaborados buscaram atender, primeiramente, a formação de mestres em enfermagem em uma disciplina obrigatória de metodologia do ensino superior realizada por meio remoto, na qual se propõe o desenvolvimento das competências dos discentes por meio da elaboração e avaliação de proposta de um curso à distância/atividades síncronas e assíncronas, no caso, contemplar as competências para a elaboração de uma Scoping Review.

O uso da plataforma Google Classroom e do Google Meet possibilitaram disponibilizar materiais, interagir e avaliar os cursistas, por meio de aulas expositivas, interpretação e exposição da temática pelo ministrante, primou-se também pelo uso de metodologias ativas, objetivando melhor entendimento do aluno.

A aplicação do estudo dirigido no curso foi uma das metodologias ativas utilizada para o ensino na dimensão cognitiva. A escolha justificou-se por ser uma atividade na qual o cursista responde às questões inerentes ao assunto, favorece 
um melhor entendimento da temática ministrada, a partir de exercícios e questões que exigem do aluno criatividade e aplicabilidade do conhecimento adquirido (Okane \&Takahashi, 2006).

Os métodos de avaliação utilizados atenderam aos pressupostos de compreensão da avaliação como um mecanismo fundamental para sondar/classificar o processo contínuo de aprendizagem do aluno. Considerou-se o caráter formativo e somativo da metodologia aplicada, pois destacou-se na experiência vivenciada, a importância da utilização de métodos capazes de avaliar conhecimento, habilidades e atitudes, na perspectiva de proporcionar reflexões que orientem uma aprendizagem significativa (Miranda et al., 2018).

As diferentes estratégias de avaliação adotadas objetivaram contemplar as três dimensões que caracterizam as aptidões concebidas pelos alunos a fim de favorecer o desenvolvimento de competências. O mapa conceitual foi utilizado para avaliar o aluno na dimensão cognitiva, a tutoria para avaliação de habilidades, atitudes e cognição e a autoavaliação na dimensão atitudinal. Para avaliar o desenvolvimento do processo de aprendizagem, aplicou-se o pré-teste e o pós-teste. As oportunidades de aprendizagem e mecanismos de avaliação pressupõem a formação sólida dos temas propostos.

Durante o desenvolvimento do curso, o mapa conceitual foi utilizado como uma estratégia avaliativa, em virtude de ser uma ferramenta que permite a organização e representação de uma fonte de conhecimento, fundamentada na teoria de aprendizagem significativa de David Ausubel (Alves, 2009, Bittencourt et al., 2013, Macedo et al., 2018).

A dinâmica da construção dos mapas ocorreu conforme preconizado na literatura. Os alunos precisaram identificar os conceitos-chave do assunto estudado; a informação deveria ser apresentada numa ordem descendente de importância; começar com os conceitos mais gerais e terminar com os conceitos mais específicos; estabelecer relação entre os conceitos por meio de linhas e identificá-las com uma ou outra palavra que explicitem essa relação; identificar conceitos e palavras que devem ter um significado ou expressam uma proposição; buscar estabelecer relações horizontais e cruzadas (Aguiar \& Correia, 2013, Anastasiou \& Alves, 2009, Macedo et al., 2018).

A utilização do mapa foi vista em sua grande maioria como positiva, que resultou na aprendizagem dos estudantes e fixação do conteúdo ministrado, apesar dos estudantes apresentaram dificuldade na utilização de ferramentas digitais mais complexas e optarem por outras ferramentas, o que configurou uma das maiores dificuldades na implementação da estratégia e observação da diferença de estágios dos cursistas no uso de tecnologias.

Quanto à experiência de tutoria, cabe destacar que foi de grande relevância na condução do curso, por ser uma abordagem promotora de maior interação virtual entre aluno-tutor, apesar do distanciamento geográfico existente entre ambos. Essa estratégia permite que todos os envolvidos desempenhem papel ativo no processo de ensinar e aprender, pois coloca o aluno como agente principal do seu processo de aprendizagem e o tutor como agente mediador para facilitar o aprendizado, incentivando e estimulando a participação do aluno durante o curso (Angelim et al., 2019).

Compreendendo que o ensino centrado na estudante demanda a adoção de métodos de avaliação condizentes com a proposta, optou-se pela aplicação do questionário de auto avaliação. Esse instrumento envolve o aprendiz no processo avaliativo, promove autonomia, autocrítica e responsabilidade com seu próprio aprendizado (Mansur \& Alves, 2018, Lopes, 2018, Ribeiro et al., 2021).

Foi possível identificar por meio do instrumento, aspectos relativos ao desempenho e o que poderia ser melhorado para favorecer a aprendizagem e assim os alunos consideraram ter contemplado os objetivos de aprendizagem propostos. Através do uso de instrumentos de autoavaliação os estudantes conseguem administrar o seu progresso individual, identificando seus aspectos positivos e suas fragilidades, melhorando seus conhecimentos, habilidades e atitudes mais fragilizadas (Oliveira et al., 2014; Santos et al., 2020).

Com base no desempenho apresentado no pré-teste e pós-teste, percebe-se a apreensão de conhecimento e desenvolvimento das competências estabelecidas, demonstrando eficácia da metodologia de ensino empregada. Esse 
instrumento pode ser aplicado de modo formativo e/ou somativo, permite constante avaliação tanto dos métodos de ensino como da compreensão do progresso ou dificuldade apresentada pelo aluno, direcionando a abordagem do conteúdo por parte do professor/tutor (Liell et al., 2020).

Nessa perspectiva, torna-se relevante destacar a contribuição da construção e desenvolvimento de um curso à distância para a formação dos discentes de programas de mestrado acadêmico. Dada a importância desta formação para a docência, práticas como essa estimulam o desenvolvimento de competências, habilidades e atitudes, favorecendo reflexões sobre todo o processo de aprendizagem ao longo da formação, principalmente ao desenvolver cursos no novo cenário mundial.

No entanto, desafios foram vivenciados durante o desenvolvimento do curso, como a falta de experiência da tutoria em educação à distância que gerou ansiedade, questionamentos, discussão e aprimoramento teórico sobre qual o papel do tutor. Apesar do grande avanço tecnológico da sociedade contemporânea percebe-se a necessidade do ensino superior em desenvolver nos docentes os elementos dessa evolução metodológica. Os tutores e alunos mesmo conhecendo e utilizando diariamente as tecnologias educacionais, ainda necessitam superar algumas barreiras relacionadas ao preconceito, ampliar o conhecimento das ferramentas educacionais e utilizá-las de maneira adequada.

Os diálogos precisam ser adaptados para as aulas online e muitos alunos ainda não apresentam habilidade de comunicação por meio de plataformas. O que empreende maior esforço dos tutores para aumentar confiança do estudante e respeito nas falas, bem como, entender as demandas e dificuldades destes.

É desafiador motivar os estudos individuais, quando são nítidas a insegurança e a dependência histórica do ensino presencial, no qual há atuação do professor no acompanhamento presencial para guiar o passo a passo a ser seguido. Tal realidade mostra que os estudantes ainda apresentam dependência do ensino tradicional e presencial.

\section{Conclusão}

A experiência proporcionou a vivência de planejamento e implementação de um curso com relevância para a comunidade acadêmica. A oportunidade de atuar como aprendizes de docentes no ensino superior foi fundamental para as mestrandas refletirem sobre a importância dos professores e da sua relação com os alunos, possibilitando um olhar crítico diante do processo ensino aprendizagem essencial para a formação docente.

As metodologias ativas tiveram destaque na construção e aplicação do curso apresentando-se como principal estratégia utilizada para alcance de uma aprendizagem significativa que contemplassem os principais aspectos da temática do curso. As competências foram alcançadas, visto que os alunos demonstraram entendimento ao final de cada módulo na resolução das atividades propostas.

A utilização de plataformas digitais como o Google Classroom e Google Meet e de ferramentas tecnológicas e softwares constituíram-se um desafio pela falta de experiência das tutoras com seu uso na modalidade de ensino à distância, entretanto, estas ferramentas foram essenciais no cenário atual em que esta modalidade de ensino faz-se necessária e, ao permitirem o desenvolvimento da autonomia do aluno, que está à frente da condução do seu processo de aprendizagem.

A vivência da tutoria permitiu aos mestrandos o desenvolvimento de uma percepção mais ampla do papel do tutor, valorizando a sua atuação como educador, orientador, coordenador e até motivador do aluno. Percebe-se a necessidade de estabelecer uma comunicação contínua para estimular o estudo e desenvolvimento das atividades; por isso reforça-se a importância da figura do tutor no processo de ensino aprendizagem.

Os materiais produzidos pelas tutoras, os métodos de avaliação adotados e as estratégias de ensino utilizadas foram bem aceitas pelos alunos e permitiram o desenvolvimento de competências propostas pelo curso favorecendo o processo de aprendizagem. 
Recomenda-se a realização de estudos adicionais apresentando a prática de novas estratégias ativas para somar conhecimentos sobre fragilidades, potencialidades e vivências em cursos à distância, bem como estudos que considerem a perspectiva do aluno.

\section{Referências}

Aguiar, J. G., \& Correia, P. R. M. (2013). Como fazer bons mapas conceituais? Estabelecendo parâmetros de referências e propondo atividades de treinamento. Revista Brasileira de Pesquisa em Educação em Ciências, 13(2), 141-157.

Alves, E. D. L. (2009), Mapa conceitual: uma forma de otimização do processo de ensino-aprendizagem. Universitas Humanas, 6(2), $105-112$.

Anastasiou, L. G. C., \& Alves, L. P. (2009). Estratégias de ensinagem. Univille.

Andrade, D. R. S. B., \& Benati, M. A. F. N. O (2019). Revolução na educação do ensino superior no Brasil: EAD. Revista Saberes, 9(1), 1-8.

Angelim, R. C. M., Brandão, B. M. G. M., Pereira, V. M. A. O., Freire, D. A., \& Abrão, F. M. S. (2019). Educação à Distância no Ensino Superior: Relato de Experiência em Estágio de Docência. Revista de Enfermagem do Centro Oeste Mineiro, 9, e2672.

Bittencourt, G. K. G. D., Nóbrega, M. M. L., Medeiros, A. C. T., \& Furtado, L. G. (2013). Mapas conceituais no ensino de pós-graduação em Enfermagem: relato de experiência. Revista Gaúcha de Enfermagem, 34(2), 172-176.

Brasil. (1996). Decreto N. ${ }^{\circ}$ 2.494, de 10 de fevereiro de 1998 . Regulamenta - Lei $\mathrm{n}^{\circ} \quad 9.394$, de 20 de dezembro de 1996. http://portal.mec.gov.br/seed/arquivos/pdf/tvescola/leis/D2494.pdf.

Brasil. (2020). Nota Técnica Ensino a Distância na Educação Básica frente a Pandemia da COVID-19.2020. https://www.todospelaeducacao.org.br/_uploads/_posts/425.pdf. Acesso dia 22 de agosto 2020.

França, T., Rabello, E. T., \& Magnago, C. (2019). As mídias e as plataformas digitais no campo da Educação Permanente em Saúde: debates e propostas. Saúde debate, 43(1), 106-115.

Liell, C. C., Bayer, A., \& Ledur, J. R. (2020). Aprendizagem significativa de conceitos básicos de cinemática no ensino fundamental. Revista de Educação, Ciências e Matemática, 10(1), 57-77.

Lopes, I. N. F. (2018). A prática da autoavaliação no ensino superior. Revista Multidisciplinar e de Psicologia, 12(39), 839-850.

Lourenço, R. G., Fornari, L. F., Santos, D. L. A., \& Fonseca, R. M. G. S. (2019). Community interventions related to intimate partner violence among adolescents: scope review. Revista Brasileira de Enfermagem, 72(1), 277-86.

Macedo, K. D. S., Acosta, B. S., Silva, E. B., Souza, N. S., Beck, C. L. C., \& Silva, K. K. D. (2018). Active learning methodologies: possible paths to innovation in health teaching. Escola Anna Nery, 22(3), 1-9.

Mascarenhas, V. H. A., Caroci-Becker, A., Venâncio, K. C. M. P., Baraldi, N. G., Durkin, A. C., \& Riesco, M. L. G. (2020). COVID-19 and the production of knowledge regarding recommendations during pregnancy: a scoping review. Revista Latino-Americana de Enfermagem, 28 , e3348.

Miranda, F. B. G., Mazzo, A., \& Pereira Junior, G. A. (2018). Assessment of individual and interprofessional skills of health professionals in simulated clinical activities: a scoping review. Interface, 22(67), 1221-34.

Okane, E. S. H., \& Takahashi, R. T. (2006). O estudo dirigido como estratégia de ensino na educação profissional em enfermagem. Revista da Escola de Enfermagem da USP, 40(2), 160-169.

Pereira, A. S., Shitsuka, D. M., Parreira F. J., \& Shitsuka, R. (2018). Metodologia da pesquisa científica. UFSM.

Peters, M. D. J., Godfrey, C., McInerney, P., Munn, Z., Tricco, A. C., \& Khalil, H. (2020). Revisões do escopo. In E. Aromataris, \& Z. Munn (Eds), JBI Manual for Evidence Synthesis. https://synthesismanual.jbi.global

Ribeiro, B. Q., Tiroli, C. F., Bolorino, N., Souza, A. B. F., González, A. D., Dellaroza, M. S. G., Freitas, F. M. B., Ferreira, N. M. A., Ribeiro, L. C. G., Montanha, R. M., Pereira, D. A., Stieven, A. S., \& Pieri, F. M. (2021). As estratégias para avaliação de aprendizagem empregadas em estudantes de enfermagem de ensino superior: revisão integrativa. Research, Society and Development, 10(3), 1-14.

Santos, F. F. D., Miranda, C. Z. D., Pertile, K. C., Barbosa, M. S., Caldeira, A. P., \& Costa, S. D. M. (2020). Desempenhos na Área de Competência Educação em Saúde: Autoavaliação de Estudantes de Medicina. Revista Brasileira de Educação Médica, 44(3), e085.

Mansur, A. F. U., \& Alves, A. C. (2018). A importância da avaliação por pares e autoavaliação em ABP aplicada a um curso de administração. Revista Íbero Americana de Estudos em Educação, 13(1), 456-473. 